\title{
UN DOCUMENTO SOBRE LA EXPULSIÓN DE LOS JUDÍOS DE CASTELLÓN DE LA PLANA
}

JOSÉ RAMÓN MAGDALENA NOM DE DÉU

Universidad de Barcelona

Hace ya bastantes años, al realizar bajo la dirección de mi querido maestro Fernando Díaz Esteban -a la sazón catedrático en Barcelona - mi trabajo de memoria de licenciatura sobre la aljama judaica de Castellón de la Plana ', incluí en el apéndice documental un curioso texto ${ }^{2}$ referente a la expulsión de los judíos castellonenses y que, ahora hace ya un siglo, había sido publicado por el cronista local Juan Antonio Balbás ${ }^{3}$. Dicho documento debía de custodiarse en el Archivo Municipal de Castellón, pues así lo afirma taxativamente el propio Balbás: «... hemos encontrado en el Archivo municipal de Castellón una carta dirigida á los Jurados de esta villa en 27 de Julio de 1492, por Lorenzo Gascó, jurado, y Jaime Agramunt, síndico de la misma, enviados, misatgers, á Valencia, para que entendieran en las causas instruidas á los judíos para el pago de los censos que se les exigía. A continuación copiamos algunos párrafos..." 4 .

El caso es que, por más que entonces rebusqué entre los viejos manuales y papeles de aquel archivo, no pude dar con el citado documento, de manera que me limité a copiar servilmente el texto de Balbás s.

'Se tituló La Aljama de judios de Castellón de la Plana en la Baja Edad Media. (Estado critico de la cuestión, rectiflcaciones, novedades y documentos para su historia). [Barcelona 1976] y fue posteriormente publicada por la "Sociedad Castellonense de Cvltura" bajo nuevo título: La Aljama Hebrea de Castellón de la Plana en la Baja Edad Media, Castellón de la Plana 1978.

${ }^{2}$ La Aljama, documento número 37, págs. 176-178.

3 J. A. BalbÁs, El Libro de la Provincia de Castellón, Castellón de la Plana 1892, págs. 147-149.

4 Ibid., pág. 147.

${ }^{5}$ Así lo publiqué en La Aljama, y en la signatura indicaba con un signo de interrogación que acaso el documento fuese de un Llibre de Concells desaparecido o extraviado. 
Al fallecer mi buen amigo el Dr. Leopoldo Piles Ros -que fue Profesor de Historia de la Universidad Literaria de Valencia, pionero en los estudios de historia judaica del reino y conocido colaborador de la revista Sefarad-, la familia me legó todos sus ficheros, carpetas y papeles. $Y$ he aquí que, curiosa casualidad, entre cientos de fotocopias y documentos transcritos apareció ante mis ojos la carta original que en su día tuvo en sus manos Juan Antonio Balbás y que fragmentariamente $-y$ con algunos errores- publicó en 1892.

Y aquí se edita íntegramente -excepto algunos fragmentos apolillados o rotos - acompañada de una reproducción fotográfica.

[recto]

Senyors molt magnifichs: hir partits de Castello arribam a Murvedre, e alli/ nos fonch feta relacio molt largament de tot lo que fins en aquella hora era/ stat fet e negociat en les causes dels juheus, axi en aquesta ciutat/ de Valencia com en la dita vila de Murvedre. E senyaladament/ que en les dites causes dels juheus sols eren jutges los batle e justicia de la dita vila, e algun altre official noy tenia res que veure, e axi/ per lo spectable Loctinent General era stat provehit e manat als dits/ jutges que en les dites causes administrassen compliment de justicia,/ e si algun dubte los occoreja se prenguessen algun juriste por asessor,/ com lo Senyor Rey non haia assignat ne destinat algu, jatsia la/ fama en Castello sia stada altra, pero la veritat es aquesta: que los/ jutges se prenen los asessors que volen. E axi los dits jutges, per als dubtes/ quels occorien havien fet venir a Murvedre lo magnifich micer/ Pere Valçanell tot sol per quels consellas, e fins en aquella hora nos/ havia declarat cosa alguna sobre los censals salvo que havien declarat/ los juheus esser tenguts pagar totes les taches reals degudes e deve dores dites per tots los cinch anys. Veritat es quens es stat significat/ que tenien sentiment declararien los censals de la aljama deures pagar/ e quitar dels bens mobles dels dits juheus. E axi hui som arribats/ en Valencia, e trobam nos ab Abram Legem \adelantat/ e ab Devosal, juheus de aquexa/ juheria als quals diguem que per a les dos hores apres mig jorn fossen/ davant lo magnifich micer Pere Miquel, com asessor del magnifich Regent/ de Governador e jutge de les causes dels dits juheus en aquexa Governacio per la assignacio/ que en Castello per lo dit magnifich Regent nos era stada feta, per esser davant/ aquell. Los quals, ab gran superbia respongueren que noy volien/ esser sino davant micer Valçanell e micer Ros, e que al dit micer/ Pere Miquel tenien per sospitos. Per mi, Lorenç Gasco, los fonch respost/ que los dit micer Valçanell e micer Ros noy tenien res que fer, car/ 
lo jutge era lo Governador e aquell volia nos hoys son asessor e que sis parla/ dels dits micer Valçanell e micer Ros, fonch per quant se deỳa que aquells/ eren stats asignats e deputats en asessors dels jutges dels dits juheus/ pero puxs aquells no tenen tal comissio no tenien res que fer en les dites/ causes, e axi la dita assignacio era per adavant lo dit asessor de Governador. Finalment, que bravegaren e cridaren tant que tota la gent del carrer/ se avalota, dient que hirien cridant via fora davant lo dit Loctinent General/ quels volien rescatar/e axis partiren. Enapres, nosaltres som stats a la assignacio davant micer/ Pere Miquel e aquelles noy son compareguts [...] havem [...]sda contra e/ per lo dir micer Pere es stat provehit quels sia feta altra assignacio per adema/ a les dos hores, ab comminacio que endesidia e contra sua hi sera provehit per justicia/

[verso]

E axi anam ab hun porter per fer los intimar la dita assignacio e trobam los/ en la posada del dit Loctinent General, als quals per lo dit porter la dita assignacio/ fonch feta ab la dita comissio. Respongueren que noy consentien com tinguessen al dit/ micer Pere per molt sospitos e que davant lo dit Loctinent General se veuria tot per avis./ Apres de tot aço yo he conferit de nostra justicia ab lo magnific micer Sart, lo qual/ me ha respost que si en Murvedre se declara que los juheus sien tenguts pagar/ e quitar los censals de la aljama dels bens, que per semblant seran tenguts/ los de Castello quitar, per lo quels tocara per sou e liura dels censals carregats/ sobre la universitat de Castello, en altra manera que ell ho te per dubtos, per semblant/ fo stat ab mon cosi micer Artes, e no havem pogut conferir axi com fora stat/ mester so restat que per stanit de vespre sia ab ell e comunicarem largament/ $E$ per quant tenim crehença que los juheus suplicaran de aquestes causes, sera/ molt mester que decontinent, vista la present, comuniqueu aquella al/ dit magnific Regent de Governador e li demaneu de gracia que faça una letra/ al dit magnific micer Pere Miquel, dientli que la voluntat sua com a jutge/ de les causes dels dits juheus es que aquell sols com asessor los hoja e/ que us dexe les sues comissions real o dels reals seus inquisidors, e que de continent,/ per home propri o altra persona segura, les nos trametau per poder mostrar/ al dit Loctinent General o a qui mester sera lo poder quel dit regent de Governador/te de las dites causes per forma quey puga obtenir compliment de nostra justicia./ E no occorrent nos altres coses, a present nos comanam molt a tots. De Valencia a XXVII de juny any M CCCC LXXXXII

Els vostres misatgers que manar podeu: Lorenç Gasco, Jurat, e Jaume Agramunt, sindich 
[al revés, a pie de folio ]

Als molts magnifichs e savis senyors los honrats [...] Jurats de la vila

de Castello

\section{RESUMEN}

Publicación completa de una carta de 27 de julio de 1492, dirigida a los Jurados de Castellón de la Plana, referente al pago de los censos que se exigía a los judíos.

\section{SUMMARY}

This article presents the publication of a letter of 27 th July 1492, addressed to the Jurados of Castellón de la Plana, referring to the payment of certain rent charges that was required of the Jews. 


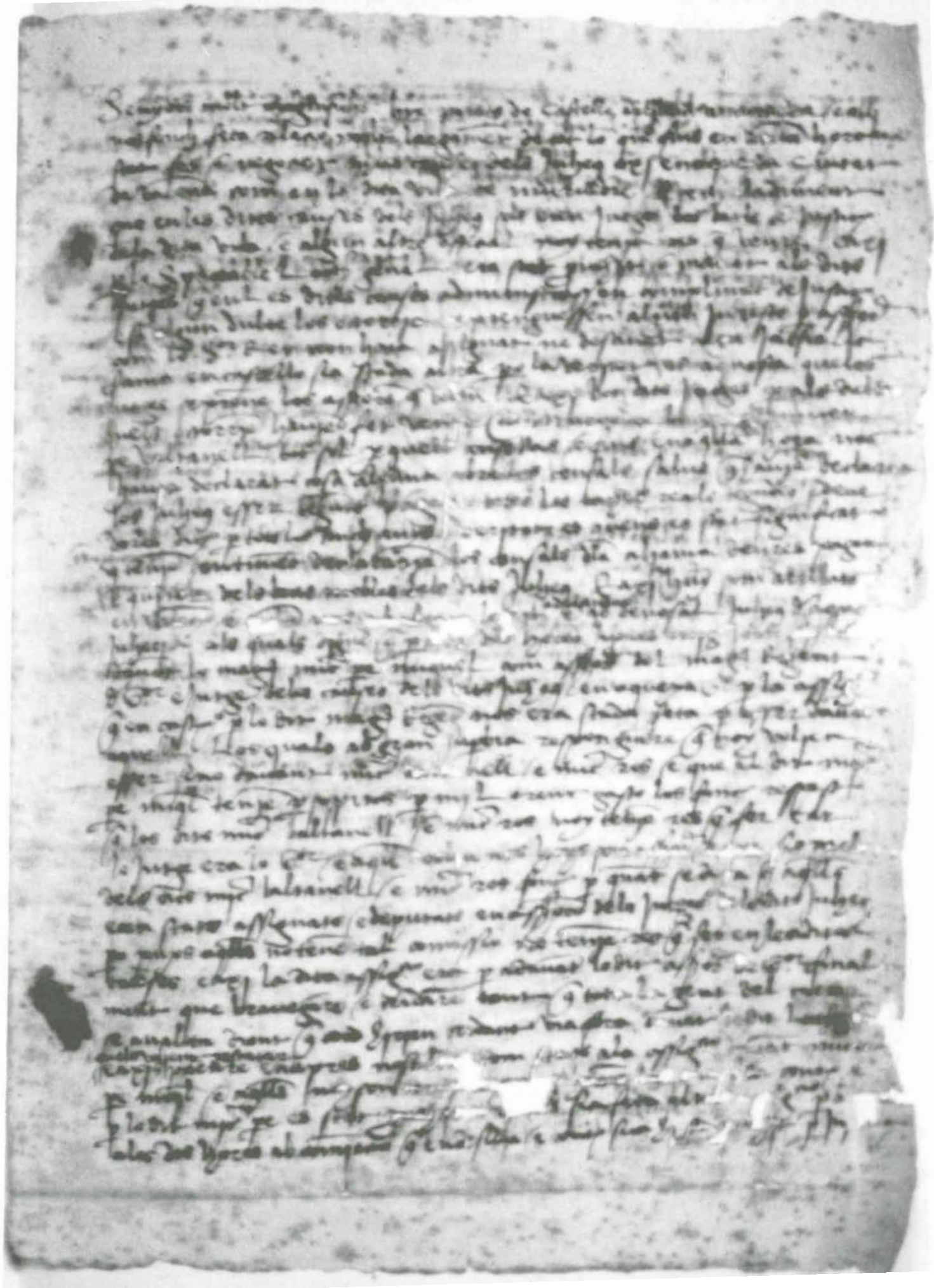

Recto 


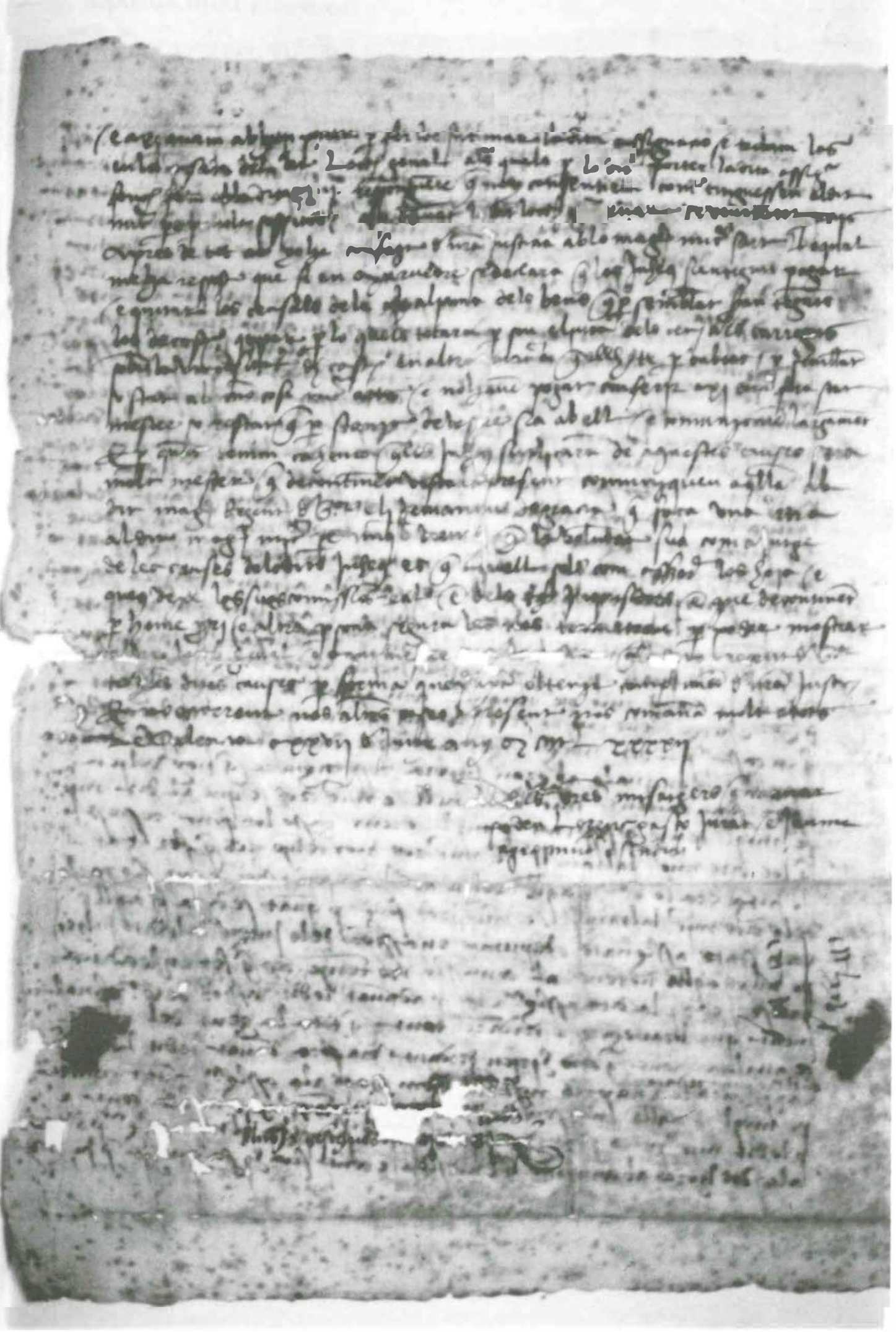

Verso 